\title{
Thermal Chemistry of Hydrazine on Clean and Oxygen- and Water- Predosed Cu(110) Single-Crystal Surfaces
}

\author{
Yunxi Yao and Francisco Zaera \\ Department of Chemistry, University of California, Riverside, CA 92521, USA \\ *Corresponding author, Email: zaera@ucr.edu
}

\begin{abstract}
The chemistry of hydrazine on $\mathrm{Cu}(110)$ single-crystal surfaces was probed under ultrahigh vacuum (UHV) conditions by temperature-programmed desorption (TPD) and X-ray photoelectron spectroscopy (XPS). Survey TPD experiments identified molecular nitrogen and ammonia as the main desorbing products from thermal activation of the adsorbate, but small amounts of diazene and $\mathrm{NH}_{2}$. radicals were also detected. At saturation coverages $\mathrm{N}_{2}$ production leads $\mathrm{NH}_{3}$ desorption by approximately $10 \mathrm{~K}$ (with TPD peaks at 350 versus $360 \mathrm{~K}$, respectively), indicating a preference for dehydrogenation over $\mathrm{N}-\mathrm{N}$ bond scission steps, and additional nitrogen was seen at even lower temperatures $(320 \mathrm{~K})$ in experiments starting with even higher doses of hydrazine. On the other hand, the formation of $\mathrm{NH}_{3}$ and $\mathrm{NH}_{2}$, which desorb in a wide range of temperatures between approximately 300 and $700 \mathrm{~K}$, dominates in experiments with low $\mathrm{N}_{2} \mathrm{H}_{4}$ doses, presumably because a stronger interaction of the $\mathrm{N}-\mathrm{N}$ bond with the metal in the flat adsorption geometry expected at such low coverages. Adsorption at room temperature seems to also facilitate the dissociative adsorption, albeit via dehydrogenation
\end{abstract}


steps that lead to the subsequent production of more significant amounts of diazene and of molecular hydrogen (in addition to $\mathrm{N}_{2}, \mathrm{NH}_{3}$, and $\mathrm{NH}_{2} \cdot$ ). Preadsorption of oxygen on the $\mathrm{Cu}(110)$ surface helps stabilize the hydrazine, increasing its desorption temperature and helping with the low-temperature $(320 \mathrm{~K})$ production of $\mathrm{N}_{2}$. Coadsorption of hydrazine with water leads to facile proton exchange, as indicated by the production of $\mathrm{NH}_{2} \mathrm{D}$ in TPD experiments with $\mathrm{N}_{2} \mathrm{H}_{4}+\mathrm{D}_{2} \mathrm{O}$. This isotope scrambling must occur at cryogenic temperatures, because all water desorbs from the surface below $200 \mathrm{~K}$ and no other changes in surface chemistry are observed after that. The implications of all this chemistry to practical applications that may use hydrazine in surface reactions with copper, including its use as a reducing agent in atomic layer deposition (ALD) processes, are discussed.

Keywords: Hydrazine, Copper Single-Crystal Surface, Predosed Oxygen, Water, Thermal Programmed Desorption, X-Ray Photoelectron Spectroscopy, Diazene.

\section{Introduction}

The thermal chemistry of hydrazine on metal surfaces has elicited some attention over the years in connection with a number of applications. Early work used hydrazine as a convenient precursor for the formation of $\mathrm{NH}_{2}$ (ads) and $\mathrm{NH}($ ads) surface species, likely intermediates in key catalytic reactions such as ammonia synthesis, and the formation of such intermediates was indeed corroborated by using several surface-sensitive techniques. For instance, Grunze speculated, based on UV (UPS) and X-ray (XPS) photoelectron spectroscopy data, that $\mathrm{N}_{2} \mathrm{H}_{4}$ 
dissociation on $\mathrm{Fe}(111)$ surfaces leads to the formation of $\mathrm{NH}_{2}$ (ads) species at $220 \mathrm{~K}$ [1], and Menzel and coworkers proved convincingly, by using a combination of high-resolution electron loss spectroscopy (HREELS), temperature programmed desorption (TPD), low-energy electron diffraction (LEED), and work function measurements, that a similar sequence takes place on $\mathrm{Ru}(001)$ [2]. In contrast, studies on $\mathrm{Pt}(111)$ indicated that hydrazine decomposition occurs via $\mathrm{N}-\mathrm{H}$, not $\mathrm{N}-\mathrm{N}$, bond breaking, to produce $\mathrm{N}_{2}$ intramolecularly and ammonia via hydrogenation of $\mathrm{N}_{2} \mathrm{H}_{y}$ surface fragments [3-5]. The chemistry on $\mathrm{Rh}(100)$ [6] and $\mathrm{Rh}(111)$ [7; 8] seems to fall in between that on $\mathrm{Fe}$ and $\mathrm{Pt}$, with evidence for both $\mathrm{N}-\mathrm{N}$ dissociation and ammonia production as well as $\mathrm{N}-\mathrm{H}$ bond scission steps, in the case of $\mathrm{Rh}(111)$ to produce diazene. Diazene, which is an interesting species in its own right because, as the parent of azo compounds, is an important transient intermediate both in gas-phase reactions and in the selective hydrogenation of multiple bonds in organic molecules, was also detected from activation of hydrazine on $\mathrm{Ni}(100)$ [9]. More esoteric mechanisms, including the production of molecular nitrogen via an intermolecular reaction involving two hydrazine adsorbates, have been proposed as well [10; 11].

Another early use of hydrazine has been as a source of nitrogen atoms to prepare surface nitrides. In connection with that application, Kiskinova and Goodman reported the successful formation of an atomic nitrogen surface layer on a $\mathrm{Ni}(100)$ single-crystal surface via the activation of hydrazine at $600 \mathrm{~K}$, at which point molecular hydrogen evolves into the gas phase [10]. On the other hand, Gland and coworkers determined, using vibrational spectroscopy, that hydrazine decomposition on $\mathrm{Ni}(111)$ results in the formation of a $\mathrm{NH}(\mathrm{ads})$ stable intermediate between 285 and $365 \mathrm{~K}$ [12]. More commonly, studies on surface nitridation have been carried out on semiconductor surfaces such as $\operatorname{Si}(111)-(7 \times 7)[13]$ and $\operatorname{Si}(100)-(2 \times 1)$ [14]. In those cases, 
dehydrogenation steps were shown to precede the scission of the $\mathrm{N}-\mathrm{N}$ bond, even if ultimately both types of reactions were proven possible, and the formation of a $\mathrm{Si}_{3} \mathrm{~N}_{4}$ layers was evidenced.

A third application of hydrazine in surface science and catalysis is as a reactive and carbon- and oxygen-free source of hydrogen [15-18]. Hydrazine may be used as a monopropellant, in which case decomposition is typically promoted by iridium dispersed on a granular alumina support [19;20], and also in fuel cells [21;22], for which a corrosion-resistant metal such as copper is highly desirable [23]. More recently, hydrazine has been proposed as an effective reducing agent in materials science synthesis. For instance, the selective reactivity of hydrazine as a reducing agent with several capping agents in colloidal solutions has been used to design processes for the formation of size- and shape-controlled metallic nanoparticles [24-27]. Hydrazine has also been introduced as both a reducing agent and a source of nitrogen for the atomic layer deposition (ALD) of thin films on metal and metal nitride surfaces [28; 29].

Our interest in the surface chemistry of hydrazine on $\mathrm{Cu}$ surfaces derives primarily from a new report on the use of such reducing agent, in combination with formic acid, in the ALD of copper films [30;31]. One of our long-term goals is to develop a mechanistic understanding of how such co-reactants operate in conjunction with metalorganic precursors in ALD [32;33]. We have also extended our work to probe the interaction of hydrazine with atomic oxygen and with water on the $\mathrm{Cu}$ surface in order to acquire additional insights into the surface chemistry related to some of the other catalytic systems mentioned above, including hydrogen production, which apparently works in gas phase but not in solution [16;17]. Interestingly, there is virtually no experimental work on the thermal chemistry of hydrazine on copper surfaces (none, to the best of 
our knowledge, other than a brief early mention on copper films [34]), yet there have been extensive discussion in the literature about this system from a computational point of view [3539]. The activation energy for the scission of the $\mathrm{N}-\mathrm{N}$ bond in $\mathrm{Cu}(111)$ was estimated at approximately $57 \mathrm{~kJ} / \mathrm{mol}$, reasonably low even if higher than on $\mathrm{Fe}(110), \mathrm{Co}(0001)$, or $\mathrm{Ni}(111)$ [39], and the resulting $\mathrm{NH}_{2}$ (ads) dissociated species were found to be thermodynamically more stable than molecularly adsorbed $\mathrm{N}_{2} \mathrm{H}_{4}$ [37]. Unfortunately, most quantum mechanics studies on copper to date have focused on the initial adsorption step of $\mathrm{N}_{2} \mathrm{H}_{4}$ on the surface, and do not provide information on the relative reactivity of the $\mathrm{N}-\mathrm{N}$ versus $\mathrm{N}-\mathrm{H}$ bonds or on the relative stability of the different potential surface intermediates. In our experimental results, we find that the main desorbing products from thermal activation of hydrazine adsorbed on $\mathrm{Cu}(110)$ are $\mathrm{N}_{2}$, and $\mathrm{NH}_{3}$, indicating that both types of bond scissions are feasible on that surface. More details follow.

\section{Experimental Details}

All of the experiments reported here were performed in a stainless-steel ultrahigh vacuum (UHV) chamber turbopumped to a base pressure in the low $10^{-10}$ Torr range and equipped with an Extrel quadrupole mass spectrometer for TPD experiments and a 50-mm radius VSW hemispherical electron-energy analyzer and an aluminum anode $(\mathrm{h} v=1486.6 \mathrm{eV})$ for X-ray studies, as described elsewhere [40-42]. A Cu(110) single crystal, a disk $10 \mathrm{~mm}$ in diameter and $1 \mathrm{~mm}$ in thickness, was mounted on a concentric manipulator via thin tantalum wires wedged into side slots made in the crystal for this purpose and fixed to the ends of copper vacuum 
feedthroughs in order to be able to cool down to $\bullet 80 \mathrm{~K}$ and to resistively heat to up to $1100 \mathrm{~K}$. The temperature was measured by using a K-type thermocouple wedged into a hole drilled on the side of the crystal, and controlled using a homemade proportional-integral-derivative (PID) circuit.

For the TPD experiments, the ionizer of the mass spectrometer is encased inside a cylindrical stainless-steel box with a 7-mm-diameter front aperture to selectively probe the gases that desorb from the crystal surface. The mass spectrometer is interfaced to a personal computer in a set up capable of following the evolution of the partial pressures of up to 15 different masses in a single TPD run. A constant heating rate of $5 \mathrm{~K} / \mathrm{s}$ was employed. For the XPS experiments, the electron-energy analyzer was set to a $50-\mathrm{eV}$ constant pass energy for an overall resolution of approximately $1.5 \mathrm{eV}$ FWHM and an accuracy in peak position of approximately $0.1 \mathrm{eV}$. Binding energies (BEs) are all referenced to a value of $932.4 \mathrm{eV}$ for the $\mathrm{Cu} 2 \mathrm{p}_{3 / 2}$ peak of metallic copper [43]. The peak areas in Figure 7 were converted into monolayers $(1 \mathrm{ML}=1$ surface species per exposed $\mathrm{Cu}$ atom) based on the intensities of the $\mathrm{Cu} 2 \mathrm{p}_{3 / 2}$ peak for the clean $\mathrm{Cu}(110)$ surface and reported relative sensitivities for the different photoelectrons [44]. Because of the approximations made (layered distribution of elements, etc.), the absolute values may not be fully reliable, but our focus is on the relative signal intensities, used to estimate the extent of the surface chemistry observed in each temperature range.

The surface of the crystal was cleaned before each experiment by sequential cycles of $\mathrm{Ar}^{+}$ion sputtering and annealing until it was deemed clean by XPS. Anhydrous hydrazine was purchased from Sigma-Aldrich (reagent grade, 98\% purity), and distilled in situ within the gas 
manifold via several freeze-pump-thaw cycles right before use. Perdeuterated water $\left(\mathrm{D}_{2} \mathrm{O}\right)$ was also obtained from Sigma-Aldrich (99.9\% isotope purity), and purified the same way. Oxygen gas was purchased from Liquid Carbonic (Research Purity, >99.995\%) and used as supplied. Dosing of the sample was done by backfilling of the chamber using leak valves, and is reported in Langmuirs ( $1 \mathrm{~L}=1 \times 10^{-6}$ Torr sec), uncorrected for differences in ion gauge sensitivities. The pressure in the main UHV chamber was measured by using a nude ion gauge.

\section{Results}

The thermal chemistry of hydrazine on clean $\mathrm{Cu}(110)$ was first probed by TPD. Figure 1 shows typical data, in this case for a $4.0 \mathrm{~L}$ dose at $140 \mathrm{~K}$, from surveying experiments designed to identify the main desorbing products and their basic temperature profiles. In addition to molecular desorption, which is seen in most traces and is best identified by the sharp peak around $170 \mathrm{~K}$ in the $32 \mathrm{amu}$ trace, the main species evolving into the gas phase are manifested by mass spectrometry signals in the spectra for 16,17 , and 28 amu. The 28 amu signal shows an intense peak at approximately $350 \mathrm{~K}$ corresponding to the desorption of $\mathrm{N}_{2}$, as corroborated by the weaker peak with similar shape and position in the 14 amu trace (atomic nitrogen) and by the absence of any signal in the $12 \mathrm{amu}$ data (ruling out any carbon-containing species). The traces for 16 and 17 amu look quite similar, with an early peak at $\sim 360 \mathrm{~K}$ followed by a broad feature covering the temperature range from 300 to approximately $700 \mathrm{~K}$, and are both associated mainly with ammonia desorption (any interference from water is ruled out by the absence of signal in the $18 \mathrm{amu}$ trace). There is a slight signal intensity excess in the $16 \mathrm{amu}$ trace not 
accounted for by the intensity in the 17 amu data around the broad feature on the hightemperature side, indicating the desorption of additional species containing $\mathrm{NH}_{2}$ moieties, most likely $\mathrm{NH}_{2} \cdot$ radicals, and also a weak (but reproducible) broad desorption between approximately 250 and $400 \mathrm{~K}$ in the 29 amu trace, which strongly suggests the formation of a small amount of diazene $\left(\mathrm{HN}=\mathrm{NH}\right.$, or $\left.\mathrm{N}_{2} \mathrm{H}_{2}\right)$. Interestingly, there is virtually no $\mathrm{H}_{2}$ production in this system: a small amount of $\mathrm{H}_{2}$ is perhaps detected around $350 \mathrm{~K}$, but if so the signal is within the experimental noise. There may be some additional $\mathrm{N}_{2}$ desorption seen in the 28 amu at high temperatures, at about or above $900 \mathrm{~K}$, which could correspond to recombination of residual atomic nitrogen from full dehydrogenation of $\mathrm{NH}_{\mathrm{x}}(\mathrm{ads})$ species, but that could also be the result of an experimental artifact.

Figure 2 summarizes the desorption data for the main species detected from thermal activation of $\mathrm{N}_{2} \mathrm{H}_{4}$ on $\mathrm{Cu}(110)$ as a function of exposure. The left panel, which reports molecular desorption (as followed by the signal for $32 \mathrm{amu}$ ), only shows one low temperature peak starting at $170 \mathrm{~K}$ and shifting slightly to higher temperatures with increasing doses that is most likely associated with condensed hydrazine. Notice that molecular desorption only starts at $\mathrm{N}_{2} \mathrm{H}_{4}$ exposures of approximately $4 \mathrm{~L}$, indicating that the adsorbates at low coverages undergo total thermal decomposition. In terms of the $\mathrm{N}_{2}$ desorption reported in the second panel of Figure 2, the main peak seen at $350 \mathrm{~K}$ is not seen at low coverages but fully develops by $4.0 \mathrm{~L}$, and remains invariant in terms of both intensity and position upon further increases in hydrazine dose. In addition, a second feature develops around $330 \mathrm{~K}$ by $15 \mathrm{~L}$. It appears that crowding of the surface helps with the dehydrogenation of $\mathrm{N}_{2} \mathrm{H}_{4}$ to $\mathrm{N}_{2}$, perhaps by forcing the chemisorbed hydrazine molecules into a perpendicular adsorption configuration that maximizes $\mathrm{N}-\mathrm{H}$ 
activation. Less likely, that second TPD feature may be the result of an intermolecular reaction between species in the first and second monolayers, as suggested for other metals in the past [10; $11]$.

The evolution of the TPD for ammonia, which was followed by recording the signal for $17 \mathrm{amu}$, is shown as a function of hydrazine initial exposure in the third panel of Figure 2. Ammonia is the main product at low coverages, but its formation is partially suppressed as the hydrazine dose is increased. Below $3 \mathrm{~L}$, most of the $\mathrm{NH}_{3}$ is detected at high temperatures, in two broad features peaking at around 440 and $550 \mathrm{~K}$, respectively. However, by $4 \mathrm{~L}$ those TPD features decrease significantly in size, and are replaced in part by a better-defined new feature at $360 \mathrm{~K}$, a temperature a few degrees higher than that of the $\mathrm{N}_{2}$ TPD peak. The evolution of molecular nitrogen and ammonia in this early temperature regime may be connected, but there is a slight delay in the production of the latter with respect to the former, indicating a preference for dehydrogenation steps before any $\mathrm{N}-\mathrm{N}$ bond scission takes place. It is also interesting to note that the hydrogen atoms released by the $\mathrm{N}_{2}$ production seem to all be consumed by the production of ammonia (which may take place via recombination of $\mathrm{NH}_{2}$ (ads) with $\mathrm{H}(\mathrm{ads})$ ), because no $\mathrm{H}_{2}$ evolution is seen in the TPD. For hydrazine doses below $4 \mathrm{~L}$, where virtually no molecular nitrogen desorption is detected, ammonia production is accompanied by the release of $\mathrm{NH}_{2}$. species, as clearly seen in the traces for 16 amu after correcting for the cracking pattern of $\mathrm{NH}_{3}$ (Figure 2, last panel). It is likely that further dehydrogenation, to $\mathrm{NH}($ ads) and $\mathrm{N}$ (ads), takes place in this low-dose regime as well, since such steps are needed to account for the stoichiometry implied by the production of ammonia at these low surfaces coverages of hydrazine. No $\mathrm{NH}_{2}$. desorption is seen above $4 \mathrm{~L}$. 
More extensive hydrazine thermal activation can be induced by carrying out the adsorption at higher surface temperatures. Figure 3 displays the data from a TPD obtained after dosing $10 \mathrm{~L}$ of $\mathrm{N}_{2} \mathrm{H}_{4}$ onto a $\mathrm{Cu}(110)$ surface held at $300 \mathrm{~K}$. Several significant differences are observed. For one, most of the chemistry observed in the TPD peaks occurs at higher temperatures (compared to what is reported in Figures 1 and 2), presumably because extensive dehydrogenation takes place during the room-temperature uptake leading to more strongly bonded surface species. All ammonia, $\mathrm{NH}_{2} \cdot$, and molecular nitrogen are produced, almost congruently, in two temperature peaks at approximately 430 and $470 \mathrm{~K}$. Moreover, some $\mathrm{H}_{2}$ is now seen to desorb in the same temperature range, and diazene is clearly detected in the 29 amu trace, at slightly lower temperature than the other products.

The effect of coadsorbed water and/or coadsorbed oxygen on the thermal chemistry of hydrazine on $\mathrm{Cu}(110)$ was tested next. The TPD traces for a 5.0 $\mathrm{L} \mathrm{N}_{2} \mathrm{H}_{4}$ dose on the appropriate surfaces are reported in Figure 4. The first panel corresponds to the chemistry on the clean surface, and follows the trends discussed above: the main desorbing species are molecular $\mathrm{N}_{2} \mathrm{H}_{4}$ at $175 \mathrm{~K}, \mathrm{~N}_{2}$ production at $350 \mathrm{~K}$, and $\mathrm{NH}_{3}$ desorption in a well-defined peak at $\sim 360 \mathrm{~K}$ and in a long hightemperature tail extending from 400 to $700 \mathrm{~K}$. The second panel displays the results from an experiment carried out on a surface predosed with $0.5 \mathrm{~L}$ of $\mathrm{D}_{2} \mathrm{O}$ at low temperatures. It is well know that water does not bond strongly to clean copper and desorbs from the first monolayer at about $165 \mathrm{~K}$ and from multilayers around $155 \mathrm{~K}$ (Figure 5, left panel) [45]. It appears that coadsorption with hydrazine does not alter that chemistry, since the same molecular desorption is seen in that case (Figures 4, second panel, and 5, left panel), and since no other (deuterated) 
water desorption peaks are seen in the TPD data. Moreover, the production of $\mathrm{N}_{2}$ and ammonia follow the same kinetics as on the clean copper, as expected if all the water desorbs at low temperatures. On the other hand, a significant amount of $\mathrm{NH}_{2} \mathrm{D}$ is seen in these experiments. The most likely explanation is that the coadsorbed $\mathrm{N}_{2} \mathrm{H}_{4}$ and $\mathrm{D}_{2} \mathrm{O}$ undergo isotope scrambling, possibly via hydrogen bonding, at very low temperatures, before the water desorbs. A small peak is also seen at $360 \mathrm{~K}$ in the 2 amu trace, but it is not clear if this is due to $\mathrm{H}_{2}$ production, or, more likely, to cracking of $\mathrm{NH}_{2} \mathrm{D}$ in the mass spectrometer.

Clean copper surfaces are fairly unreactive toward thermal activation of adsorbed acidic or basic organic molecules such as water, formic acid or ammonia, but can be activated via the addition of small amounts of atomic oxygen $[42 ; 45 ; 46]$. The third panel in Figure 4 shows the TPD data obtained from a surface dosed with $5.0 \mathrm{~L}$ of $\mathrm{N}_{2} \mathrm{H}_{4}$ after predosing it with $0.1 \mathrm{~L}$ of $\mathrm{O}_{2}$ (all at 140 K). A few significant differences are seen when comparing with the traces from the clean $\mathrm{Cu}(110)$ surface. First, oxygen seems to stabilize molecular adsorption: in addition to the sharp $170 \mathrm{~K}$ peak in the 32 amu trace due to desorption of condensed $\mathrm{N}_{2} \mathrm{H}_{4}$, significant additional intensity is seen all the way to $\sim 500 \mathrm{~K}$, with a peak at $260 \mathrm{~K}$. Moreover, the presence of oxygen on the surface seems to facilitate the low-temperature $(320 \mathrm{~K}) \mathrm{N}_{2}$ peak, which is seen on the clean copper surface only after much higher $\mathrm{N}_{2} \mathrm{H}_{4}$ doses. Additional nitrogen is still produced at $350 \mathrm{~K}$, and ammonia detected at $360 \mathrm{~K}$ and then in a range extending to $\sim 700 \mathrm{~K}$, as on the clean substrate. Lastly, the coadsorption of all three water, oxygen, and hydrazine reactants results in TPD equivalent to the sum of the other data discussed above (Figure 4, right panel). Water adsorption is stabilized by the coadsorbed oxygen, leading to a broader multipeak feature below $200 \mathrm{~K}$, as also seen with the two adsorbates alone (Figure 5, right panel). However, no water 
production from $\mathrm{OH}(\mathrm{ads})$ recombination around $280 \mathrm{~K}$ is seen in our example in Figure 4 (with hydrazine), as it occurs with coadsorbed $\mathrm{O}$ (ads) and $\mathrm{OH}($ ads) alone (Figure 5, right panel) [45]. There is also no water retention on the surface above $300 \mathrm{~K}$, at which point only the chemistry of hydrazine coadsorbed with oxygen is observed, namely, $\mathrm{N}_{2}$ production at 320 and $350 \mathrm{~K}$, and ammonia formation at $360 \mathrm{~K}$ and then in a broad feature up to $700 \mathrm{~K}$. Once again, $\mathrm{NH}_{2} \mathrm{D}$ from low-temperature isotope exchange with $\mathrm{D}_{2} \mathrm{O}$ is detected, as in the case with $\mathrm{N}_{2} \mathrm{H}_{4}+\mathrm{D}_{2} \mathrm{O}$ in the second panel of Figure 4, and a peak is also observed in the 2 amu trace. No new chemistry was seen as a product of any unique synergy among all three adsorbed species.

Finally, the reactivity of $\mathrm{N}_{2} \mathrm{H}_{4}$ on clean and oxygen-treated $\mathrm{Cu}(110)$ surfaces was investigated further by using XPS. The relevant data are reported in Figure 6 in the form of $\mathrm{N}$ 1s (two left panels) and $\mathrm{O} 1 \mathrm{~s}$ (right panel) peaks as a function of annealing temperature for $5.0 \mathrm{~L}$ of $\mathrm{N}_{2} \mathrm{H}_{4}$ dosed on clean (left panel) and oxygen-predosed (two right panels) surfaces, and a summary of the relative peak areas and XPS peak positions is provided in Figure 7. The XPS results are in general consistent with the conclusions derived from the TPD data. First, a $\mathrm{N}$ 1s peak for hydrazine multilayers condensed at low temperatures is seen at $400.6 \mathrm{eV}$ binding energy, a value within the range of those reported previously for this compound in the literature $[1 ; 3 ; 6 ; 14 ; 34$; 47-49]. In addition, after molecular desorption below $200 \mathrm{~K}$, the main changes are seen between 300 and $400 \mathrm{~K}$ in the form of a reduction in N 1s XPS peak intensity and a peak shift, correlating with the evolution of $\mathrm{N}_{2}, \mathrm{NH}_{3}$, and $\mathrm{NH}_{2}$. seen in the TPD in the same temperature range (Figures 1, 2, and 4). A slow $\mathrm{N} \mathrm{1s} \mathrm{intensity} \mathrm{decrease} \mathrm{is} \mathrm{seen} \mathrm{up} \mathrm{to} \mathrm{that} \mathrm{point,} \mathrm{between} 200$ and $300 \mathrm{~K}$, possibly a reflection of the slow desorption of $\mathrm{N}_{2} \mathrm{H}_{4}$ and $\mathrm{N}_{2} \mathrm{H}_{2}$ in that temperature range. In the end, after heating to $400 \mathrm{~K}$, only a weak N 1s XPS feature centered at $401.2 \mathrm{eV}$ remains, 
corresponding to an estimated coverage of less than $0.04 \mathrm{ML}$, or less than $10 \%$ of the total nitrogen detected at the lowest temperature $(150 \mathrm{~K})$.

The XPS data for the adsorption of hydrazine on oxygen covered $\mathrm{Cu}(110)$ surfaces follow in general the same trends as on the clean copper, with a couple of noticeable exceptions, namely: (1) the $\mathrm{N} 1 \mathrm{~s}$ XPS binding energies are all red-shifted by about $0.5 \mathrm{eV}$, presumably because of the increased electron density on the surface provided by the coadsorbed oxygen atoms; and (2) the changes in N 1s XPS peak intensities are seen earlier than on the clean substrate, when heating from 300 to $350 \mathrm{~K}$ versus when going from 350 to $400 \mathrm{~K}$, presumably because the new $320 \mathrm{~K} \mathrm{~N}_{2}$ desorption that takes place according to the TPD data (in addition to the feature seen on all surfaces at $350 \mathrm{~K}$, Figure 4).

Regarding the evolution of the $\mathrm{O}$ 1s XPS signal seen upon thermal annealing of the $\mathrm{N}_{2} \mathrm{H}_{4} / \mathrm{O} / \mathrm{Cu}(110)$ surface, an initial signal decrease is seen between 150 and $200 \mathrm{~K}$. This is most likely due to desorption of coadsorbed water from the background, which may be enhanced by the coadsorbed hydrazine: the original O 1s XPS peak before hydrazine dosing corresponds to only about $0.1 \mathrm{ML}$ of atomic oxygen on the surface (as opposed to the $0.15 \mathrm{ML}$ measured at 150 $\mathrm{K}$ ), and the additional intensity, which is lost again upon heating to $200 \mathrm{~K}$, is centered at binding energies around $531.0 \mathrm{eV}$, as expected for condensed water. Between 200 and $250 \mathrm{~K}$, the $\mathrm{O} 1 \mathrm{~s}$ XPS peak shift considerably, from 529.9 to $530.8 \mathrm{eV}$, a change that we attribute to the formation of surface hydroxy $(\mathrm{OH})$ groups via hydrogen extraction from the adsorbed hydrazine, in a similar fashion as also reported with a number of amines [50; 51] and alcohols [52]. That transformation is complete by $300 \mathrm{~K}$, but an additional, subtler, change occurs between 300 and 
$400 \mathrm{~K}$, a temperature range where the $\mathrm{O} 1 \mathrm{~s}$ XPS peak position drifts from 530.8 to $531.2 \mathrm{eV}$ without changing in total intensity. This is the regime where ammonia evolves into the gas phase and other dehydrogenated species likely form on the surface, which suggests that the surface oxygen atoms may intervene in the associated hydrogen transfer steps and perhaps retain some of the $\mathrm{H}$ atoms in the form of additional $\mathrm{OH}(\mathrm{ads})$ species. Certainly, the O 1s XPS peak obtained at $400 \mathrm{~K}$ is sharper than those seen at 300 and $350 \mathrm{~K}$, reflecting the hydrogenation of some of the unreacted surface oxygen groups.

One important observation from the XPS data is that in all cases the $\mathrm{N}$ 1s XPS peaks shift to higher binding energies with increasing annealing temperatures (Figures 6 and 7). In general, this could be explained by the more positive charge expected in the more dehydrogenated species, either $\mathrm{NH}_{\mathrm{x}}(\mathrm{ads})$ or $\mathrm{N}_{2} \mathrm{H}_{\mathrm{y}}(\mathrm{ads})$, that form on the surface upon thermally activated dehydrogenation, but the trend is opposite to those reported for hydrazine on most other metal surfaces. For instance, Grunze observed that, on $\mathrm{Fe}(111)$, heating up adsorbed hydrazine from 220 to $300 \mathrm{~K}$ leads to a shift in N 1s XPS binding energy from 400.2 to $396.6 \mathrm{eV}$, a value they ascribed to adsorbed atomic nitrogen [1]. On aluminum films, Roberts and coworkers saw similar changes, from $400.3 \mathrm{eV}$ at $85 \mathrm{~K}$, to $399.5 \mathrm{eV}$ at $290 \mathrm{~K}$, presumably because of the formation of $\mathrm{NH}_{2}$ (ads), and to $398.4 \mathrm{eV}$ at $390 \mathrm{~K}$, perhaps from $\mathrm{NH}(\mathrm{ads})$ or $\mathrm{N}(\mathrm{ads})$ [48]. Finally, the group of White reported that on $\mathrm{Rh}(100)$ the initial $\mathrm{N}$ 1s XPS peak for $\mathrm{N}_{2} \mathrm{H}_{4}$ adsorbed at low temperatures, centered at $400.1 \mathrm{eV}$, shifts to $397.5 \mathrm{eV}$ at $530 \mathrm{~K}$, corresponding to the formation of atomic nitrogen [6]. The one clear exception is the work of Alberas et al., who on $\operatorname{Pt}(111)$ reported the development of a new peak at $401.5 \mathrm{eV}$ upon heating adsorbed hydrazine to $200 \mathrm{~K}$ (the peak for the original adsorbed hydrazine was seen at $400.2 \mathrm{eV}$ ) [3]. Their explanation for 
this blue shifts in the $\mathrm{N} 1 \mathrm{~s}$ XPS peak, which we think also applies to our $\mathrm{Cu}(110)$ system, is that the adsorbed hydrazine decomposes on the $\mathrm{Pt}($ and $\mathrm{Cu}$ ) surface primarily via dehydrogenation to form $\mathrm{N}_{2} \mathrm{H}_{\mathrm{y}}(\mathrm{ads})$ species, not by scission of the $\mathrm{N}-\mathrm{N}$ bond to produce $\mathrm{NH}_{\mathrm{x}}($ ads) moieties as on the other metals. In support of this interpretation, it should be mentioned that the N 1s XPS peak reported for azomethane $\left(\mathrm{CH}_{3} \mathrm{~N}=\mathrm{NCH}_{3}\right)$ adsorbed on $\mathrm{Cu}(110)$ is centered at $401.4 \mathrm{eV}$ [53], the same value we see for hydrazine on clean $\mathrm{Cu}(110)$ after heating to $400 \mathrm{~K}$. It may be that the surface species surviving on the $\mathrm{Cu}(110)$ surface above $400 \mathrm{~K}$ is chemisorbed diazene $(\mathrm{HN}=\mathrm{NH})$.

\section{Discussion}

TPD and XPS data has been provided here in support of our proposal for the mechanism of the thermal chemistry of hydrazine on clean and oxygen- and water-predosed $\mathrm{Cu}(110)$ single crystal surfaces. The main gas-phase products resulting from heating up $\mathrm{N}_{2} \mathrm{H}_{4}$ adsorbed on clean $\mathrm{Cu}(110)$ are nitrogen and ammonia, but small amounts of diazene $\left(\mathrm{N}_{2} \mathrm{H}_{2}\right)$ and $\mathrm{NH}_{2}$. radicals are detected as well. Consequently, it can be said that the copper surface promotes the scission of both $\mathrm{N}-\mathrm{H}$ and $\mathrm{N}-\mathrm{N}$ bonds in the original reactant. However, although these two families of reactions compete, the preference for one over the other is also clear and changes with initial coverage.

At low coverages, after exposures below 4.0 L, very little $\mathrm{N}_{2}$ production is seen in the TPD data and the main products are $\mathrm{NH}_{3}$ and $\mathrm{NH}_{2}$, which evolve in a wide range of temperatures starting 
at about $300 \mathrm{~K}$ and maximizing in rate at approximately 440 and $550 \mathrm{~K}$. This suggests that adsorption of hydrazine is strong at low coverages, and leads predominantly to the dissociation of $\mathrm{N}-\mathrm{N}$ bonds at relatively high temperatures. Nevertheless, ammonia production requires a source of atomic hydrogen, so the concomitant dehydrogenation of other adsorbed fragments to $\mathrm{N}_{2} \mathrm{H}_{\mathrm{y}}$ (ads), $\mathrm{NH}$ (ads) and/or $\mathrm{N}(\mathrm{ads})$ is likely. The ejection of $\mathrm{NH}_{2}$. radicals, on the other hand, takes place with retention of the original stoichiometry, and may occur via direct $\mathrm{N}-\mathrm{N}$ bond scission in molecules adsorbed at an angle from the surface plane.

At coverages near or above saturation, on the other hand, the selectivity of hydrazine decomposition on $\mathrm{Cu}(110)$ changes, and the conversion starts at lower temperatures and becomes dominated by $\mathrm{N}-\mathrm{H}$ bond-breaking steps. Several pieces of information point to this switch: (1) the evolution of molecular nitrogen becomes dominant, seen in the TPD traces first by the appearance of a peak at $350 \mathrm{~K}$ and later, at higher coverages, by the growth of a second feature at even lower temperatures, approximately $330 \mathrm{~K}$; (2) although ammonia is still produced at high coverages, the main peak lags that of $\mathrm{N}_{2}$ production, peaking at $360 \mathrm{~K}$ (there is also additional $\mathrm{NH}_{3}$ evolution until $\sim 700 \mathrm{~K}$ ); (3) the relative yields of molecular nitrogen versus ammonia in the TPD traces evolve from the predominance of ammonia at low coverages to a preference for nitrogen at saturation; (4) desorption of a small amount of diazene is seen between 250 and 400 $\mathrm{K}$ in the TPD data, and that product only requires dehydrogenation steps; and (5) the shifts of the $\mathrm{N}$ 1s XPS peaks toward higher binding energies with increasing surface temperatures are consistent with dehydrogenation steps and with the formation of chemisorbed diazene, and inconsistent with the creation of $\mathrm{NH}_{\mathrm{x}}(\mathrm{ads})$ species. The relative inability of copper to activate the $\mathrm{N}-\mathrm{N}$ bond in hydrazine compared to other transition metals is consistent with the detection of 
$\mathrm{NH}_{\mathrm{x}}(\mathrm{ads})$ surface species in most other surfaces studied to date $[1 ; 6 ; 48]$ and also with the trend for the activation energies for $\mathrm{N}-\mathrm{N}$ bond breaking estimated by DFT calculations [39], but not with the theoretical prediction that $\mathrm{N}-\mathrm{N}$ bond breaking should dominate over molecular adsorption on copper [37]. Unfortunately, no theoretical study has yet addressed the issue of relative reactivity of $\mathrm{N}-\mathrm{H}$ versus $\mathrm{N}-\mathrm{N}$ bonds in hydrazine chemisorbed on transition metals directly.

Copper surfaces are known to be relatively inactive, especially towards the thermal activation of alcohols [54], organic acids [42; 52], or bases [46; 51]. The addition of small amounts of oxygen has been shown to increase that reactivity, by facilitating deprotonation via the formation of surface hydroxy groups. This chemistry was probed here with hydrazine. It was found that, indeed, coadsorbed oxygen stabilizes the chemisorption of $\mathrm{N}_{2} \mathrm{H}_{4}$, and, perhaps more importantly, helps promote dehydrogenation steps. The latter is indicated by the development of a new $\mathrm{N}_{2}$ TPD peak at $320 \mathrm{~K}$ (Figure 4, second panel), the same feature that is seen on the clean copper surface only at higher coverages (Figure 2). It could be thought be that the new TPD feature is simply the result of surface crowding, but hydrogen transfer steps are also indicated by the shifts seen in the O 1s XPS signal after heating to high temperatures due to the formation of the $\mathrm{OH}(\mathrm{ads})$ species expected from hydrogen abstraction from the hydrazine (Figures 6 and 7). In terms of reactions with coadsorbed water, the deuterium labeling TPD experiments presented in Figure 4 (using $\mathrm{D}_{2} \mathrm{O}$ ) clearly show incorporation of deuterium into the ammonia made from hydrazine. That exchange is likely to occur at low temperatures, because all water desorbs from the surface below $200 \mathrm{~K}$, even when oxygen is added to provide further stability for both $\mathrm{D}_{2} \mathrm{O}$ 
and $\mathrm{N}_{2} \mathrm{H}_{4}$ adsorbates. No other interactions or reactions between the two adsorbates, other than this low-temperature proton exchange, were identified in our experiments.

We end with a brief discussion of the implications of the chemistry described here to the possible uses of hydrazine in relevant catalysis or materials applications. As mentioned in the introduction, hydrazines have been suggested as possible nitridation agents $[13 ; 28 ; 55 ; 56]$, but the fact that $\mathrm{N}-\mathrm{H}$ bond scission steps dominate over the activation of the $\mathrm{N}-\mathrm{N}$ bond on copper surfaces, at least at high coverages, suggests that this type of nitridation may not be particularly effective. On the other hand, the ease with which hydrazine dehydrogenates and becomes oxidized to diazene and to molecular nitrogen makes it a good and clean source of hydrogen, both as $\mathrm{H}$ (ads) on the surface and as $\mathrm{H}_{2}$ (for fuel applications [17; 23]), and also a potential reducing agent. In ALD applications in particular $[29 ; 33 ; 57 ; 58]$, hydrazine is expected to be a much more effective co-reactant than ammonia for the reduction of copper precursors to grow thin copper films. Given the difficulty of activating molecular hydrogen on copper surfaces [59; 60], hydrazine may also be a good substitute for $\mathrm{H}_{2}$ in ALD for film growth on $\mathrm{Cu}$ substrates.

The role of hydrazine in the ALD process recently proposed by the Winter group [30], which also requires formic acid and a viable copper metalorganic precursor, may be more complex, but may still involve atomic hydrogen transfer steps: the fast H-D exchange between hydrazine and $\mathrm{D}_{2} \mathrm{O}$ on $\mathrm{Cu}(110)$ seen here at cryogenic temperatures attests to the ease with which such reactions are expected to take place. Furthermore, given the difficulty shown here for hydrazine to form $\mathrm{NH}_{\mathrm{x}}(\mathrm{ads})$ surface moieties on $\mathrm{Cu}$ surfaces, it is not very likely that such intermediates participate in the ALD chemistry [31]; it is more probable for $\mathrm{N}_{2} \mathrm{H}_{\mathrm{y}}($ ads) intermediates to be 
involved instead. One possibility is for the copper formate resulting from the conversion of $\mathrm{Cu}$ precursors with formic acid to be reduced by the hydrazine according to the following stoichiometries:

$$
\begin{aligned}
& \mathrm{Cu}(\mathrm{OOCH})_{2}+\mathrm{N}_{2} \mathrm{H}_{4} \rightarrow \mathrm{Cu}(0)+2 \mathrm{HCOOH}+\mathrm{N}_{2} \mathrm{H}_{2} \\
& \mathrm{Cu}(\mathrm{OOCH})_{2}+\mathrm{N}_{2} \mathrm{H}_{2} \rightarrow \mathrm{Cu}(0)+2 \mathrm{HCOOH}+\mathrm{N}_{2}
\end{aligned}
$$

In this proposed mechanism, hydrazine acts as the sole reducing agent of the copper ions, without additional redox chemistry from either the formate ligands or formic acid, and molecular nitrogen rather than ammonia is made as the byproduct. It is still possible that some hydrazine is reduced by formic acid as well, via the stoichiometry in Equation (3) as suggested before [31]:

$$
\mathrm{N}_{2} \mathrm{H}_{4}+\mathrm{HCOOH} \rightarrow 2 \mathrm{NH}_{3}+\mathrm{CO}_{2}
$$

This idea seems feasible given that ammonia is also made during the thermal decomposition of hydrazine on $\mathrm{Cu}(110)$. Nevertheless, the surface intermediates in such case are still expected to be $\mathrm{N}_{2} \mathrm{H}_{\mathrm{y}}(\mathrm{ads})$, not $\mathrm{NH}_{\mathrm{x}}(\mathrm{ads})$, species, and the actual surface moieties promoting the reduction of hydrazine to be a formate (perhaps coordinated to the copper ion, as indicated in Equations (2) and (3)), not formic acid, which only binds weakly to copper [42]. These ideas complicate the simple mechanism initially put forward to explain the $\mathrm{Cu}$ precursor/formic acid/hydrazine ALD process [30;31], but a more complete picture of the surface chemistry involved will require still further experimental and theoretical work. 


\section{Conclusions}

Survey temperature programmed desorption (TPD) experiments with hydrazine adsorbed on a $\mathrm{Cu}(110)$ single-crystal surface at cryogenic temperatures identified the evolution of molecular hydrazine at $170 \mathrm{~K}$ as well as the production of molecular nitrogen, and ammonia at 350 and 360 and $300-700 \mathrm{~K}$ respectively. In addition, small amounts of diazene and $\mathrm{NH}_{2} \cdot$ radicals, at 250 400 and $300-700 \mathrm{~K}$ respectively, were also detected. Interestingly, no significant $\mathrm{H}_{2}$ production was observed. A set of experiments as a function of initial hydrazine dose showed a clear transition from the predominance of desorption of $\mathrm{NH}_{3}$ and $\mathrm{NH}_{2}$. at low coverages to a partial switch to $\mathrm{N}_{2}$ formation and the suppression of the radical ejection for exposures of $4 \mathrm{~L}$ and above. An additional low $(320 \mathrm{~K}) \mathrm{N}_{2}$ peak also develops in the TPD for doses above about $15 \mathrm{~L}$. Adsorption of hydrazine on $\mathrm{Cu}(110)$ at $300 \mathrm{~K}$ leads to the stabilization of surface intermediates, which now yield gas-phase products only above $400 \mathrm{~K}: \mathrm{H}_{2}, \mathrm{~N}_{2}$ and $\mathrm{NH}_{3}$ are all seen at 430 and $470 \mathrm{~K}$, and diazene at slightly lower temperatures.

Exposure of the $\mathrm{Cu}(110)$ to oxygen prior to the hydrazine uptake helps stabilize the adsorption of the latter, as indicated by the delay of some of the molecular $\mathrm{N}_{2} \mathrm{H}_{4}$ desorption to temperatures of up to $500 \mathrm{~K}$. Also, the new low-temperature $\mathrm{N}_{2}$ TPD peak, only seen after higher doses on clean $\mathrm{Cu}(110)$, is detected with $5.0 \mathrm{~L} \mathrm{~N}_{2} \mathrm{H}_{4}$ in the presence of the surface oxygen, possibly because that oxygen offers further crowding of the surface, inducing a change in adsorption geometry akin to that resulting from further hydrazine uptake. Coadsorption of $\mathrm{N}_{2} \mathrm{H}_{4}$ and $\mathrm{D}_{2} \mathrm{O}$ on either clean or oxygen-pretreated $\mathrm{Cu}(110)$ surfaces results in the production of $\mathrm{NH}_{2} \mathrm{D}$ in TPD experiments. The 
desorption kinetics of that product is the same as on the clean metal, and all water desorbs below $200 \mathrm{~K}$, in the same fashion as in $\mathrm{D}_{2} \mathrm{O} / \mathrm{Cu}(110)$, which means that the hydrazine and water must undergo isotope scrambling at cryogenic temperatures. Once water desorbs, the remaining thermal behavior of the coadsorbed system resembles that seen without any water.

XPS data provide further support for the surface chemistry established for hydrazine on $\mathrm{Cu}(110)$ from analysis of the TPD data. For one, the major intensity change in the N 1s XPS signals occurs in the same temperature range where the main TPD products, $\mathrm{N}_{2}$ and $\mathrm{NH}_{3}$, are seen, namely, around $350 \mathrm{~K}$ on clean $\mathrm{Cu}(110)$ and between 300 and $350 \mathrm{~K}$ in the $\mathrm{O} / \mathrm{Cu}(110)$ case. In addition, though, two more pieces of information were extracted from the XPS data: (1) the N 1s XPS peak shifts to higher binding energies with increasing heating temperature, indicating the prevalence of dehydrogenation steps over $\mathrm{N}-\mathrm{N}$ bond scission and the formation of $\mathrm{N}_{2} \mathrm{H}_{\mathrm{y}}(\operatorname{ads})$ intermediates, including diazene $\left(\mathrm{N}_{2} \mathrm{H}_{2}\right)$ rather than $\mathrm{NH}_{\mathrm{x}}(\mathrm{ads})$ moieties; and (2) on the oxygen pretreated surfaces, the $\mathrm{O}$ 1s XPS peak also shifts to higher binding energies with increasing temperature, as expected from the formation of surface $\mathrm{OH}$ groups via hydrogen-transfer steps. It appears that adsorbed atomic oxygen may aid in the dehydrogenation of hydrazine on $\mathrm{Cu}(110)$.

\section{Acknowledgements}

This work was supported by the U.S. Department of Energy, Office of Science, Basic Energy Sciences, Materials Science Division, under Award No. DE-SC0001839. 


\section{References}

[1] M. Grunze, Surf. Sci. 81 (1979) 603-625.

[2] H. Rauscher, K. L. Kostov, D. Menzel, Chem. Phys. 177 (1993) 473-496.

[3] D. J. Alberas, J. Kiss, Z. M. Liu, J. M. White, Surf. Sci. 278 (1992) 51-61.

[4] J. T. Ranney, J. L. Gland, Surf. Sci. 360 (1996) 112-120.

[5] J. T. Ranney, A. J. Franz, J. L. Gland, Langmuir 13 (1997) 2731-2734.

[6] W. M. Daniel, J. M. White, Surf. Sci. 171 (1986) 289-302.

[7] J. Prasad, J. L. Gland, Langmuir 7 (1991) 722-726.

[8] M. L. Wagner, L. D. Schmidt, Surf. Sci. 257 (1991) 113-128.

[9] S. X. Huang, T. S. Rufael, J. L. Gland, Surf. Sci. 290 (1993) L673-L676.

[10] B. J. Wood, H. Wise, J. Catal. 39 (1975) 471-480.

[11] H. H. Sawin, R. P. Merrill, J. Chem. Phys. 73 (1980) 996-998.

[12] J. L. Gland, G. B. Fisher, G. E. Mitchell, Chem. Phys. Lett. 119 (1985) 89-92.

[13] Y. Bu, D. W. Shinn, M. C. Lin, Surf. Sci. 276 (1992) 184-199.

[14] Y. Bu, M. C. Lin, Surf. Sci. 311 (1994) 385-394.

[15] M. Zheng, R. Cheng, X. Chen, N. Li, L. Li, X. Wang, T. Zhang, Int. J. Hydrogen Energy 30 (2005) 1081-1089.

[16] S. K. Singh, X.-B. Zhang, Q. Xu, J. Am. Chem. Soc. 131 (2009) 9894-9895.

[17] S. K. Singh, Q. Xu, Catal. Sci. Technol. 3 (2013) 1889-1900.

[18] F. Gao, A. V. Teplyakov, J. Phys. Chem. C 118 (2014) 27998-28006.

[19] G. Sutton, History of Liquid Propellant Rocket Engines, American Institute of Aeronautics \& Astronautics, inc, Reston, Virginia, 2005. 
[20] C. H. Hwang, S. N. Lee, S. W. Baek, C. Y. Han, S. K. Kim, M. J. Yu, Ind. Eng. Chem. Res. 51 (2012) 5382-5393.

[21] A. Serov, C. Kwak, Appl. Catal. B 98 (2010) 1-9.

[22] K. Asazawa, K. Yamada, H. Tanaka, A. Oka, M. Taniguchi, T. Kobayashi, Angew. Chem., Int. Ed. 46 (2007) 8024-8027.

[23] E. Granot, B. Filanovsky, I. Presman, I. Kuras, F. Patolsky, J. Power Sources 204 (2012) $116-121$.

[24] S.-H. Wu, D.-H. Chen, J. Coll. Interface Sci. 273 (2004) 165-169.

[25] I. Lisiecki, J. Phys. Chem. B 109 (2005) 12231-12244.

[26] Y. Wang, A. V. Biradar, G. Wang, K. K. Sharma, C. T. Duncan, S. Rangan, T. Asefa, Chem. - Eur. J. 16 (2010) 10735-10743.

[27] A. F. Alvarez-Paneque, B. Rodríguez-González, I. Pastoriza-Santos, L. M. Liz-Marzán, J. Phys. Chem. C 117 (2013) 2474-2479.

[28] B. B. Burton, A. R. Lavoie, S. M. George, J. Electrochem. Soc. 155 (2008) D508-D516.

[29] T. J. Knisley, L. C. Kalutarage, C. H. Winter, Coord. Chem. Rev. 257 (2013) 3222-3231.

[30] T. J. Knisley, T. C. Ariyasena, T. Sajavaara, M. J. Saly, C. H. Winter, Chem. Mater. 23 (2011) 4417-4419.

[31] G. Dey, S. D. Elliott, RSC Adv. 4 (2014) 34448-34453.

[32] F. Zaera, J. Phys. Chem. Lett. 3 (2012) 1301-1309.

[33] F. Zaera, Coord. Chem. Rev. 257 (2013) 3177-3191.

[34] M. H. Matloob, M. W. Roberts, J. Chem. Soc., Faraday Trans. 173 (1977) 1393-1405.

[35] T. D. Daff, D. Costa, I. Lisiecki, N. H. de Leeuw, J. Phys. Chem. C 113 (2009) 1571415722. 
[36] M. K. Agusta, H. Kasai, J. Phys. Jpn. 81 (2012) 124705.

[37] T. D. Daff, N. H. de Leeuw, J. Mater. Chem. 22 (2012) 23210-23220.

[38] S. S. Tafreshi, A. Roldan, N. Y. Dzade, N. H. de Leeuw, Surf. Sci. 622 (2014) 1-8.

[39] F. Fathurrahman, H. Kasai, Surf. Sci. (2015) DOI: 10.1016/j.susc.2015.1006.1025.

[40] F. Zaera, J. Vac. Sci. Technol. A 7 (1989) 640-645.

[41] T. Kim, Y. Yao, J. P. Coyle, S. T. Barry, F. Zaera, Chem. Mater. 25 (2013) 3630-3639.

[42] Y. Yao, F. Zaera, Surf. Sci. (2015) DOI: 10.1016/j.susc.2015.1006.1007.

[43] C. D. Wagner, W. M. Riggs, L. E. Davis, J. F. Moulder, G. E. Muilenberg (Eds.), Handbook of X-Ray Photoelectron Spectroscopy, Perkin-Elmer Corporation, Eden Prairie, MN, 1978.

[44] D. Briggs, M. P. Seah (Eds.), Practical Surface Analysis. Volume 1. Auger and X-ray Photoelectron Spectroscopy, John Wiley and Sons, Chichester, UK, 1990.

[45] K. Bange, D. E. Grider, T. E. Madey, J. K. Sass, Surf. Sci. 137 (1984) 38-64.

[46] B. Afsin, P. R. Davies, A. Pashusky, M. W. Roberts, D. Vincent, Surf. Sci. 284 (1993) 109120.

[47] H. Binder, D. Sellmann, Z. Naturforsch. 33b (1978) 173-179.

[48] D. W. Johnson, M. W. Roberts, J. Electron Spectrosc. Relat. Phenom. 19 (1980) 185-195.

[49] C. M. Truong, J. A. Rodriguez, D. W. Goodman, J. Phys. Chem. 96 (1992) 341-347.

[50] P. R. Davies, D. Edwards, D. Richards, Surf. Sci. 573 (2004) 284-290.

[51] P. R. Davies, D. Edwards, M. Parsons, Surf. Sci. 601 (2007) 3253-3260.

[52] P. R. Davies, M. Bowker, Catal. Today 154 (2010) 31-37.

[53] P. Chuang, Y. L. Chan, C. H. Chuang, S.-H. Chien, T. J. Chuang, Appl. Surf. Sci. 169-170 (2001) 153-159. 
[54] I. E. Wachs, R. J. Madix, Appl. Surf. Sci. 1 (1978) 303-328.

[55] M. P. Shaver, M. D. Fryzuk, J. Am. Chem. Soc. 127 (2005) 500-501.

[56] Z. Fang, H. C. Aspinall, R. Odedra, R. J. Potter, J. Cryst. Growth 331 (2011) 33-39.

[57] S. M. George, Chem. Rev. 110 (2010) 111-131.

[58] D. J. H. Emslie, P. Chadha, J. S. Price, Coord. Chem. Rev. 257 (2013) 3282-3296.

[59] Q. Ma, H. Guo, R. G. Gordon, F. Zaera, Chem. Mater. 22 (2010) 352-359.

[60] Q. Ma, F. Zaera, R. G. Gordon, J. Vac. Sci. Technol. A 30 (2012) 01A114. 


\section{Figure Captions}

Figure 1. Survey temperature programmed desorption (TPD) data from 4.0 L of hydrazine adsorbed on clean $\mathrm{Cu}(110)$ at $140 \mathrm{~K}$. Shown are traces for (from bottom to top) 2, 12, 14, 18, 29, 32, 16, 17, and 28 amu. The main desorbing species detected in these experiments are molecular nitrogen (14 and $28 \mathrm{amu}$ ), ammonia (16 and $17 \mathrm{amu})$, and molecular hydrazine (32 amu), but small amounts of diazene (29 amu) and $\mathrm{NH}_{2}$. radicals (16 amu) are seen as well.

Figure 2. TPD traces for (from left to right) $\mathrm{N}_{2} \mathrm{H}_{4}$ (32 amu), $\mathrm{N}_{2}(28 \mathrm{amu}), \mathrm{NH}_{3}(17 \mathrm{amu})$ and $\mathrm{NH}_{2} \cdot$ (16 amu, corrected for the contribution from ammonia) as a function of initial exposure from hydrazine adsorbed on clean $\mathrm{Cu}(110) . \quad \mathrm{NH}_{3}$ and $\mathrm{NH}_{2} \cdot$ desorption dominates at exposures below $4 \mathrm{~L}$, but $\mathrm{N}_{2}$ becomes the preferred product at higher doses.

Figure 3. Survey TPD from $10 \mathrm{~L}$ of hydrazine dosed on clean $\mathrm{Cu}(110)$ at $300 \mathrm{~K}$. Shown are data for (from bottom to top): 2, 14, 16, 17, 28, 29, and 32 amu. Desorption of $\mathrm{H}_{2}(2$ amu), $\mathrm{NH}_{2} \cdot(16 \mathrm{amu}), \mathrm{NH}_{3}(16$ and $17 \mathrm{amu})$, and $\mathrm{N}_{2}(14$ and $28 \mathrm{amu})$ are all seen in two stages between about 400 and $500 \mathrm{~K}$, and diazene (29 amu) is observed at slightly lower temperatures. 
Figure 4. TPD data from 5.0 L of hydrazine adsorbed on clean (left panel), perdeutero-water predosed $\left(0.1 \mathrm{~L} \mathrm{D}_{2} \mathrm{O}\right.$, second panel), oxygen predosed $\left(0.1 \mathrm{~L} \mathrm{O}_{2}\right.$, third panel), and perdeutero-water plus oxygen predosed $\left(0.1 \mathrm{~L} \mathrm{O}_{2}\right.$, then $0.5 \mathrm{~L} \mathrm{D}_{2} \mathrm{O}$, last panel $)$ at 140 K. Traces are shown in each case for (from bottom to top): 2, 17, 18, 20, 32, and 28 amu.

Figure 5. $\mathrm{D}_{2} \mathrm{O}(20 \mathrm{amu}) \mathrm{TPD}$ results from $\mathrm{D}_{2} \mathrm{O}$ adsorbed on clean (left panel) and oxygenpredosed (right) $\mathrm{Cu}(110)$. Left: TPD traces versus $\mathrm{D}_{2} \mathrm{O}$ initial exposure (1.0, 2.0, 3.0, and 6.0 L, starting from the second trace from the bottom up). The bottom spectrum, which corresponds to $5.0 \mathrm{~L} \mathrm{~N}_{2} \mathrm{H}_{4}$ dosed after $0.5 \mathrm{~L}$ of $\mathrm{D}_{2} \mathrm{O}$, is provided for comparison. Right: Top: TPD traces from 2.0 L D $\mathrm{D}_{2} \mathrm{O}$ adsorbed on a $\mathrm{Cu}(110)$ surface predosed with $0.1 \mathrm{~L} \mathrm{O}_{2}$; Bottom: data obtained after the sequential dosing of $0.5 \mathrm{~L} \mathrm{O}_{2}$, $0.5 \mathrm{~L} \mathrm{D}_{2} \mathrm{O}$, and 5.0 L of $\mathrm{N}_{2} \mathrm{H}_{4}$.

Figure 6. X-ray photoelectron spectra (XPS) from 5.0 L of $\mathrm{N}_{2} \mathrm{H}_{4}$ dosed at $140 \mathrm{~K}$ on clean (left panel) and oxygen-pretreated (two right panels) $\mathrm{Cu}(110)$. The first two panels are for the $\mathrm{N}$ 1s XPS peak, the last corresponds to the O 1s XPS signal. Traces are shown in each panel as a function of heating temperature. Two left panels (from top to bottom): $150,200,250,300,350$, and $400 \mathrm{~K}$, and blank surface (clean and oxygen predosed, respectively, taken before $\mathrm{N}_{2} \mathrm{H}_{4}$ dosing). Right panel (from top to bottom): Blank (oxygen predosed) surface, and after dosing the $\mathrm{N}_{2} \mathrm{H}_{4}$ and heating to 150, 200, 250, 300,350 , and $400 \mathrm{~K}$. Oxygen pretreatment: 1 x $10^{-6}$ Torr of $\mathrm{O}_{2}$ at $500 \mathrm{~K}$ for $10 \mathrm{~min}$. 
Figure 7. Summary of the XPS data shown in Figure 6 in the form of peak areas (left panel) and peak positions (binding energies, BEs, right) versus heating temperature. Left: $\mathrm{Cu} 2 \mathrm{p}_{3 / 2}$ (solid dark blue and open dark red squares, raw spectra not shown), $\mathrm{N} 1 \mathrm{~s}$ (solid light blue and open light red circles), and O 1s (solid purple diamonds) XPS signal intensities, corrected for differences in spectrometer sensitivities and scaled to add up to approximately one monolayer $(1 \mathrm{ML}=1$ atom/molecule per exposed $\mathrm{Cu}$ atom). The solid symbols and dashed lines correspond to the clean $\mathrm{Cu}(110)$, the open symbols and solid lines to the oxygen pre-exposed surfaces. Right: N 1s XPS peak positions versus temperature (same symbol, line and color convention as on the left). 


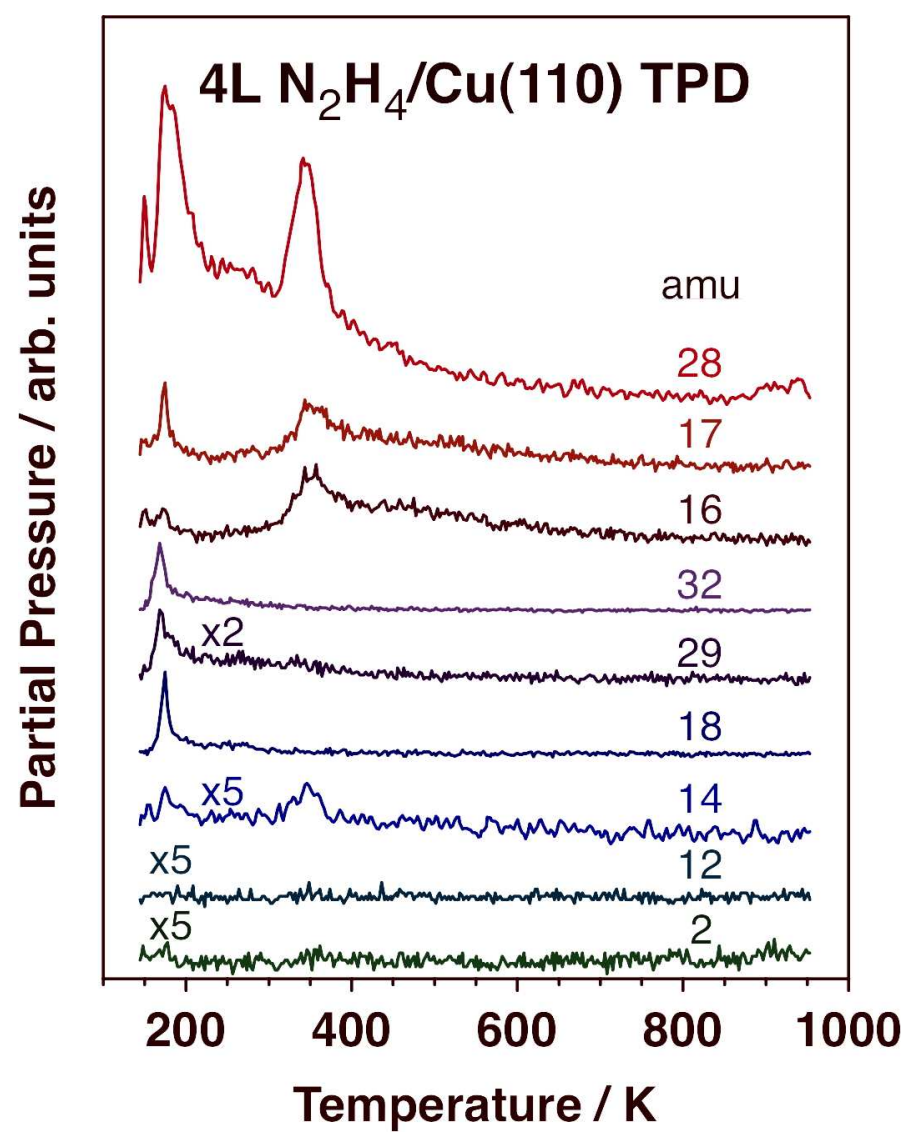

Figure 1 


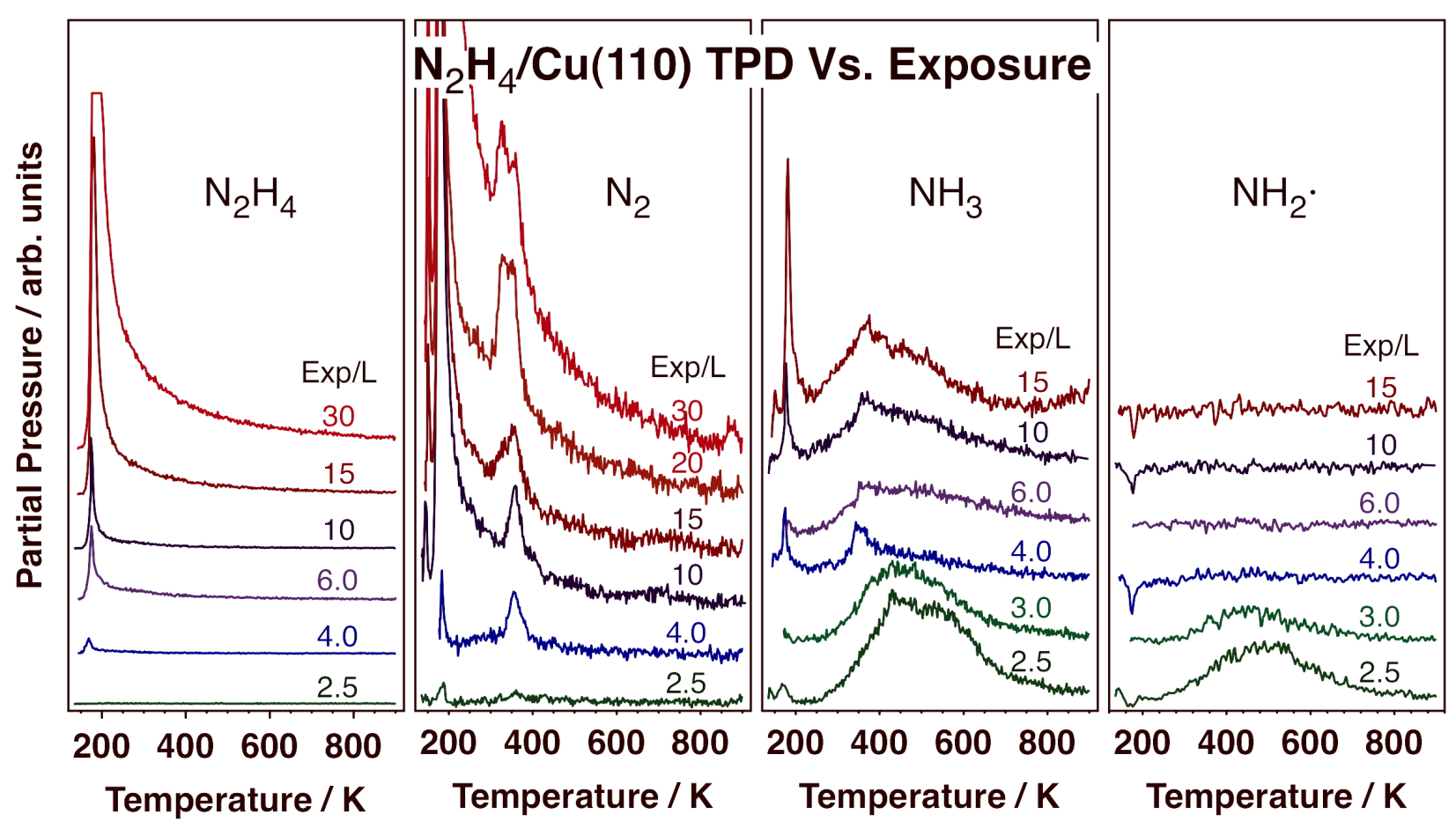

Figure 2 


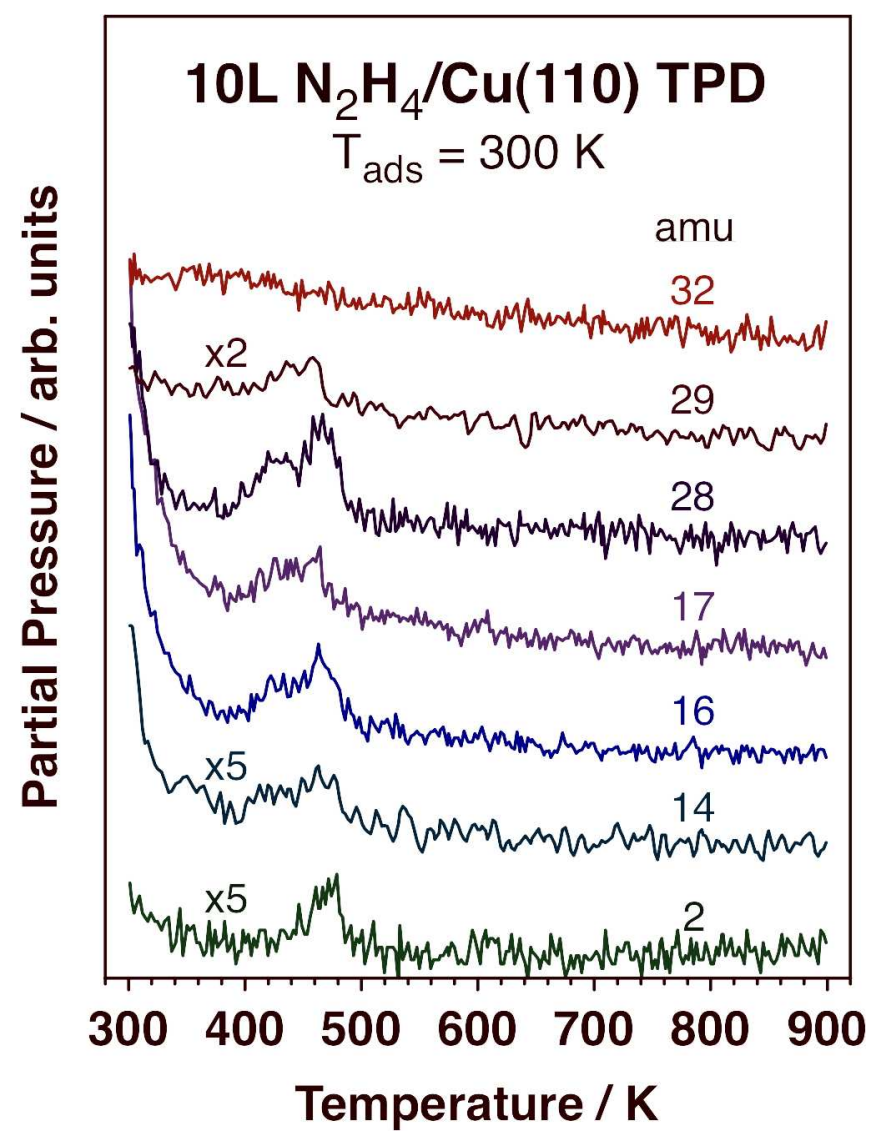

Figure 3 


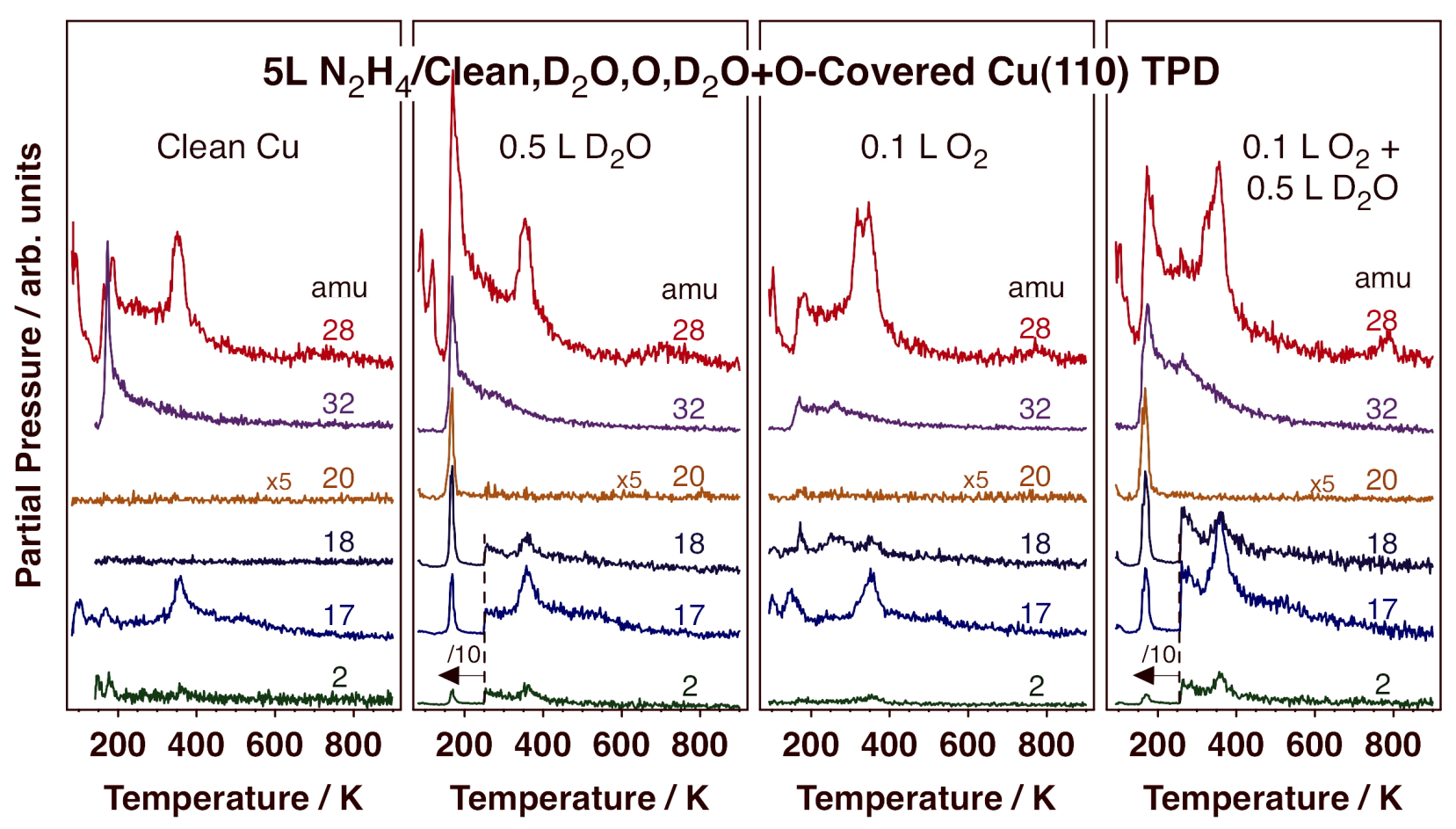

Figure 4 


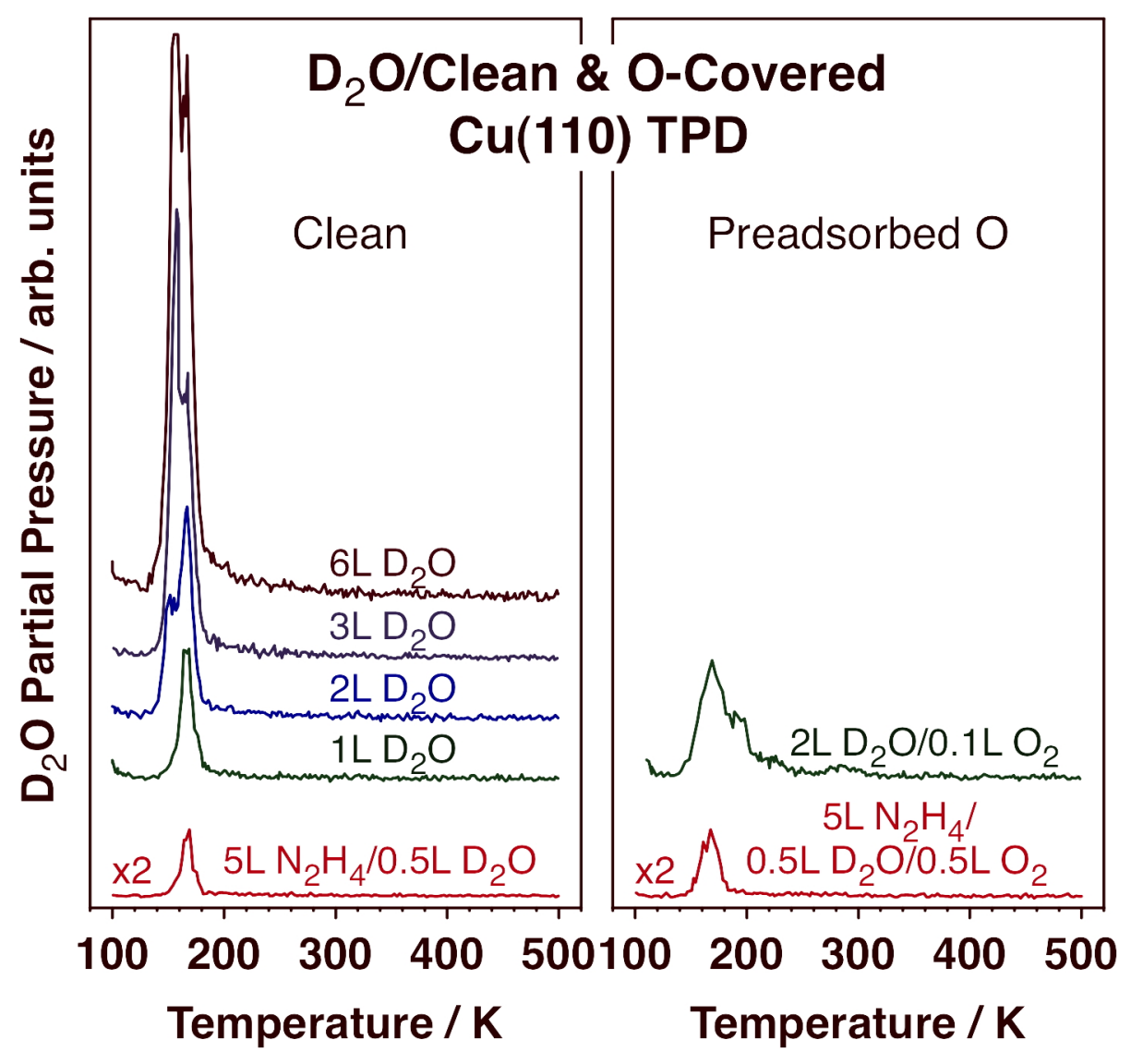

Figure 5 

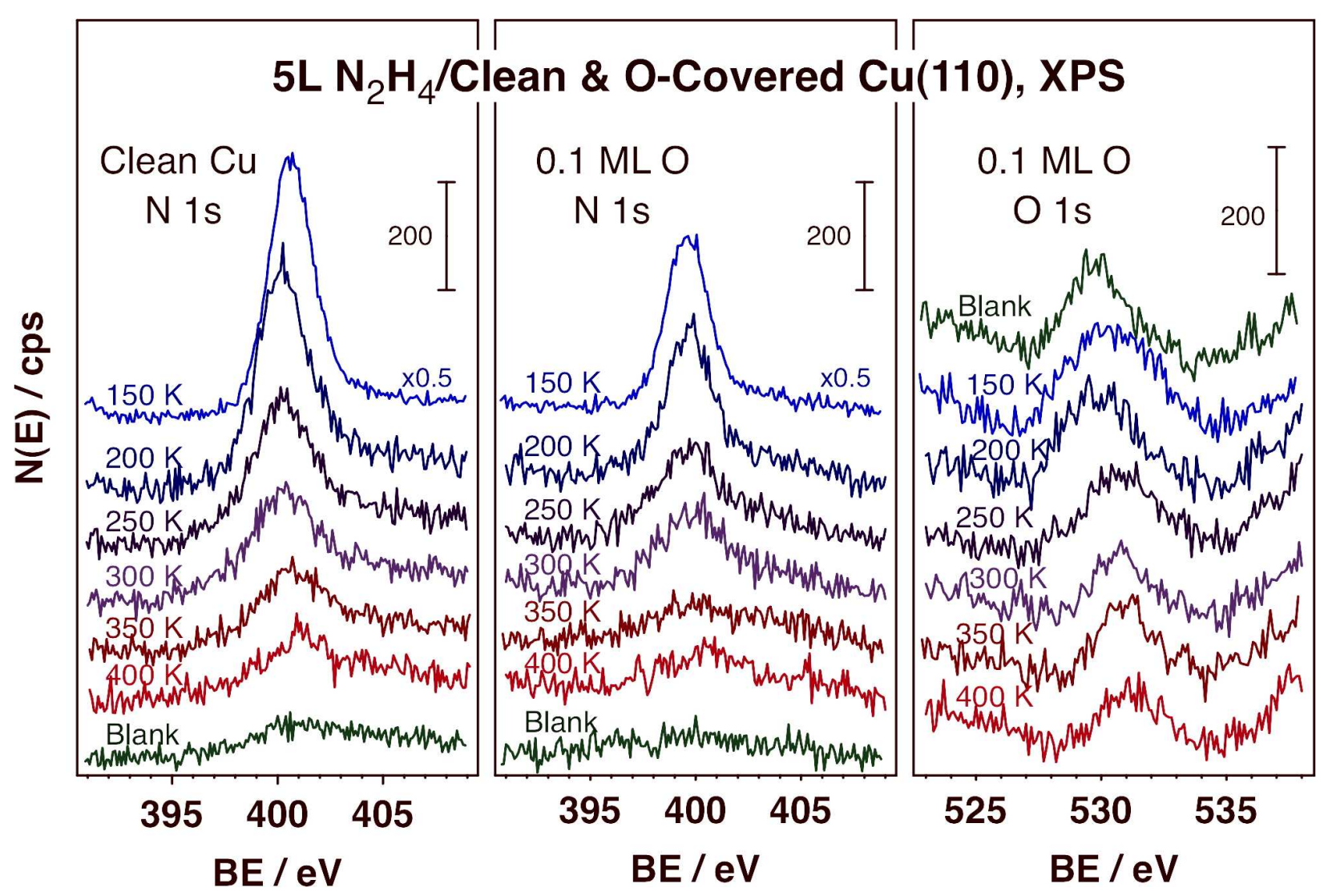

Figure 6 


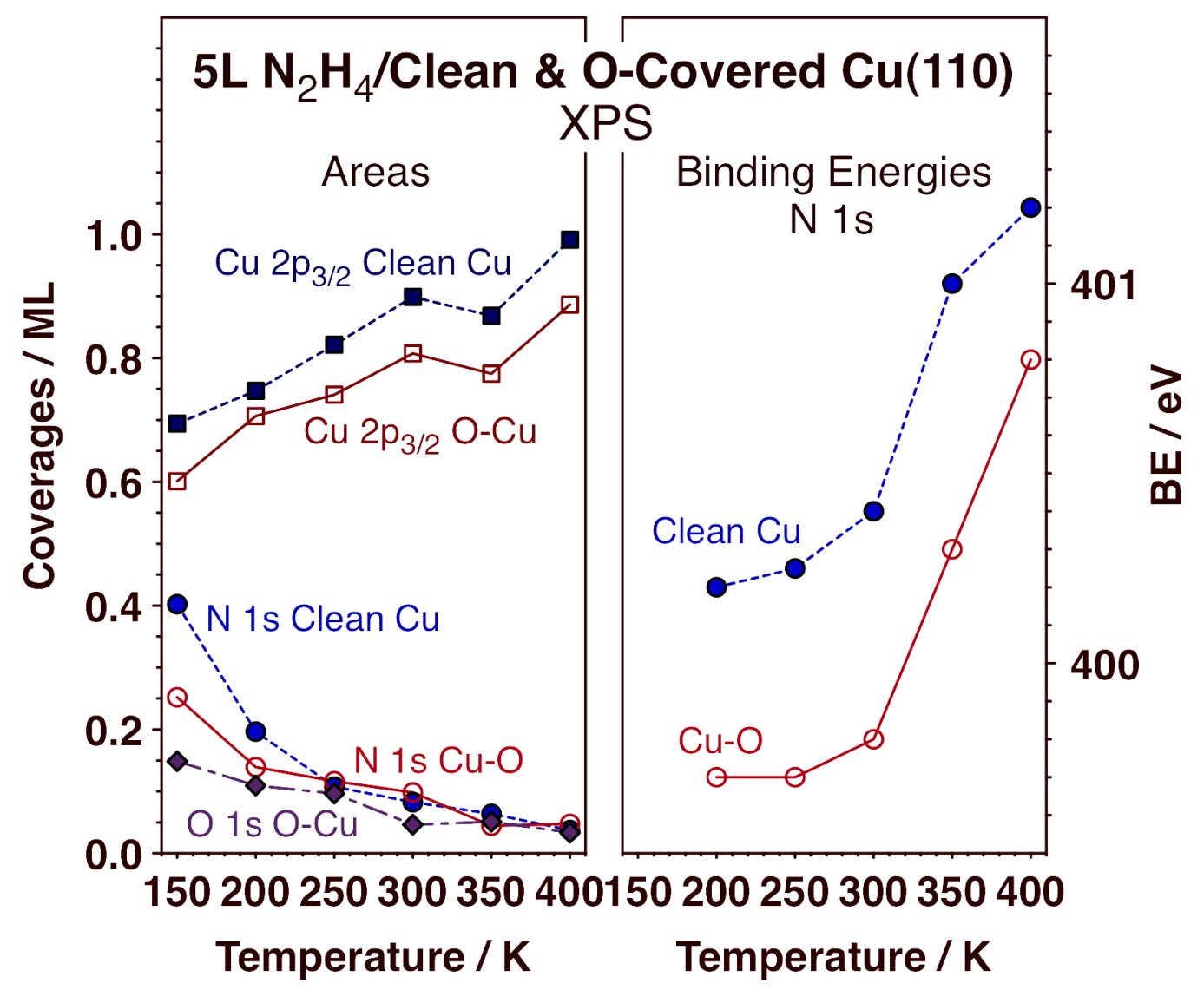

Figure 7 


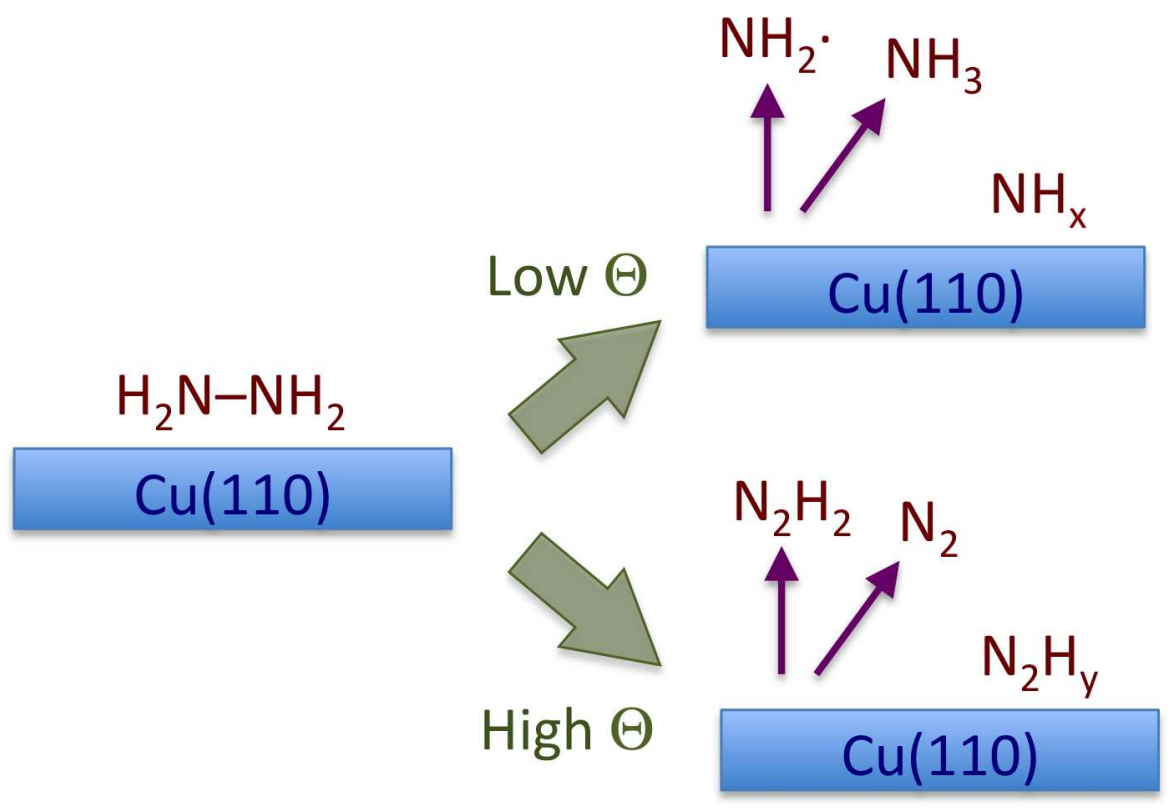

Graphical Abstract 